Article

\title{
Structural and Fluorine Plasma Etching Behavior of Sputter-Deposition Yttrium Fluoride Film
}

\author{
Wei-Kai Wang *, Yu-Xiu Lin and Yi-Jie Xu \\ Department of Materials Science and Engineering, Da-Yeh University, Changhua 51591, Taiwan; \\ h63290@gmail.com (Y.-X.L.); pa821221@yahoo.com.tw (Y.-J.X.) \\ * Correspondence: wk@mail.dyu.edu.tw; Tel.: +886-5-8511-888 (ext. 2606); Fax: +886-5-8511-666
}

Received: 28 October 2018; Accepted: 10 November 2018; Published: 14 November 2018

\begin{abstract}
Yttrium fluoride $\left(\mathrm{YF}_{3}\right)$ films were grown on sapphire substrate by a radio frequency magnetron using a commercial ceramic target in a vacuum chamber. The structure, composition, and plasma etching behavior of the films were systematically investigated. The $\mathrm{YF}_{3}$ film was deposited at a working pressure of $5 \mathrm{mTorr}$ and an RF power of $150 \mathrm{~W}$. The substrate-heating temperature was increased from 400 to $700^{\circ} \mathrm{C}$ in increments of $100{ }^{\circ} \mathrm{C}$. High-resolution transmission electron microscopy (HRTEM) and X-ray diffraction results confirmed an orthorhombic $\mathrm{YF}_{3}$ structure was obtained at a substrate temperature of $700{ }^{\circ} \mathrm{C}$ for $2 \mathrm{~h}$. X-ray photoelectron spectroscopy revealed a strongly fluorinated bond ( $\mathrm{Y}-\mathrm{F}$ bond) on the etched surface of the $\mathrm{YF}_{3}$ films. HRTEM analysis also revealed that the $\mathrm{YF}_{3}$ films became yttrium-oxyfluorinated after exposure to fluorocarbon plasma. The etching depth was three times lower on $\mathrm{YF}_{3}$ film than on $\mathrm{Al}_{2} \mathrm{O}_{3}$ plate. These results showed that the $\mathrm{YF}_{3}$ films have excellent erosion resistance properties compared to $\mathrm{Al}_{2} \mathrm{O}_{3}$ plates.
\end{abstract}

Keywords: yttrium fluoride; films; plasma processing equipment

\section{Introduction}

Silicon-oxide series of ceramics, such as $\mathrm{SiO}_{2}$ and $\mathrm{Al}_{2} \mathrm{O}_{3}$ coatings, are valued for their hardness, high wear resistance, dielectric strength, high corrosion resistance, and chemical stability. They have been extensively used as plasma-resistant materials in plasma etching equipment and in the deposition thin-film processing semiconductor industry $[1,2]$. They are also popular shield materials that protect the interior ceramic parts, chamber windows, cover baffles, rings, and reactor chamber walls of plasma equipment from corrosive fluorocarbon gases (e.g., $\mathrm{C}_{2} \mathrm{~F}_{6}, \mathrm{CF}_{4}, \mathrm{CHF}_{3}$, and $\mathrm{C}_{2} \mathrm{~F}_{6}$ ) [3]. However, on the inner walls of the processing chamber, these oxide materials easily interact with fluorine-based plasma, causing significant erosion and particle generation [4]. As integrated circuits continue to downscale to the nanoscopic level, particle contaminants in their wafers are becoming increasingly worrisome, because they short-current the integration circuit and reduce mass-production yield [5]. Yttrium oxide $\left(\mathrm{Y}_{2} \mathrm{O}_{3}\right)$ promises to replace $\mathrm{SiO}_{2}$ and $\mathrm{Al}_{2} \mathrm{O}_{3}$ as the material of plasma-facing inner walls, owing to its much higher chemical stability and reduced erosion rate [6]. Nevertheless, as pointed out by mass-production factories, $\mathrm{Y}_{2} \mathrm{O}_{3}$ inner wall coatings contain pores and crack defects that release particles into the plasma by flake-off [7]. Yttrium fluoride $\left(\mathrm{YF}_{3}\right)$ coatings have recently attracted substantial attention because their high plasma erosion resistance prevents the generation of fluoride particles on the chamber wall surface, reducing particulate contamination [8]. Moreover, $\mathrm{YF}_{3}$ reportedly has a high dielectric strength [9]. Thus, $\mathrm{YF}_{3}$ coating is a new plasma-facing material. Researchers have fabricated protective coatings in chamber walls using a plasma spray technique. However, as the spray method rapidly forms thick films with porous structures and rough surfaces, it might introduce critical particle impurities during the semiconductor plasma deposition/etching process [10]. Vacuum coating techniques such as magnetron sputtering can address these problems. 
To our knowledge, sputtered $\mathrm{YF}_{3}$ films and their erosion behavior under fluorocarbon plasma etching had not previously been investigated. Herein, we investigate the composition, structure, erosion behavior, and surface morphology changes of $\mathrm{YF}_{3}$ films on sapphire substrate, prepared by magnetron sputtering.

\section{Materials and Methods}

The sputter material was $\mathrm{YF}_{3}$ ceramic target (99.99\% purity, 2 inch diameter, $3 \mathrm{~mm}$ thickness). $\mathrm{YF}_{3}$ thin films were deposited on c-plane sapphire substrate (single crystal of $\mathrm{Al}_{2} \mathrm{O}_{3}$ ) at room temperature by radio frequency magnetron sputtering in a vacuum chamber. The substrates were cleaned before deposition, first in acetone and alcohol, and then by ultrasonic cleansing in de-ionized (DI) water for $30 \mathrm{~min}$. They were blow-dried in nitrogen gas. The sputtering gas was high-purity argon $(99.995 \%)$, maintained at a constant flow rate $(\sim 100 \mathrm{sccm})$. The sputtering process was performed under a base chamber pressure of approximately $1.5 \times 10^{-5}$ torr, with turbo molecular and oil diffusion pumps. The plasma generation was activated by RF power at $13.56 \mathrm{MHz}$. The target-substrate distance was $15 \mathrm{~cm}$. To ensure uniform film thickness, the substrate holder was rotated at $20 \mathrm{rpm}$ during the deposition process. Substrate heating temperature was varied from 400 to $700{ }^{\circ} \mathrm{C}$ in steps of $100{ }^{\circ} \mathrm{C}$. The sputter deposition conditions of the $\mathrm{YF}_{3}$ films are detailed in Table 1 . The plasma etching behaviors of all samples were performed using an inductively-coupled plasma etcher. The etching gases mixed were $\mathrm{CF}_{4}$ and $\mathrm{O}_{2}$. The etching conditions are shown in Table 2.

Table 1. Experimental parameters of sputter deposition conditions of $\mathrm{YF}_{3}$ film.

\begin{tabular}{cc}
\hline Parameters & Conditions \\
\hline RF power $(\mathrm{W})$ & 150 \\
Duration (hours) & 2 \\
Substrate temperature $\left({ }^{\circ} \mathrm{C}\right)$ & $400-700$ \\
Substrate rotation $(\mathrm{rpm})$ & 20 \\
Working pressure $(\mathrm{mTorr})$ & 5 \\
Substrate to target distance $(\mathrm{cm})$ & 15 \\
Argon gas flow rate $(\mathrm{sccm})$ & 100 \\
\hline
\end{tabular}

Table 2. Plasma etching conditions.

\begin{tabular}{cc}
\hline Parameters & Condition \\
\hline RF power $(\mathrm{W})$ & 800 \\
RF power, bias $(\mathrm{W})$ & 100 \\
Pressure $(\mathrm{mTorr})$ & 3 \\
$\mathrm{CF}_{4}(\mathrm{sccm})$ & 25 \\
$\mathrm{O}_{2}(\mathrm{sccm})$ & 5 \\
Etching time $(\mathrm{min})$ & $10,20,30$ \\
\hline
\end{tabular}

The surface morphology, microstructure, and elemental analysis of these coating samples were analyzed by scanning electron microscopy (SEM, S-3000H, Hitachi, Tokyo, Japan) coupled with energy dispersive X-ray diffraction (EDX), atomic force microscopy (AFM, DI-3100, Veeco, New York, NY, USA), and high-resolution transmission electron microcopy (HRTEM, H-600, Hitachi, Tokyo, Japan). The sample compositions were examined by X-ray photoelectron spectroscopy (XPS, PHI 5000 VersaProbe, ULVAC-PHI, Kanagawa, Japan) using a monochromatic $\mathrm{Cu} \mathrm{K} \alpha \mathrm{X}$-ray source $(\lambda=1.541874 \AA)$ at a passing energy of $20 \mathrm{eV}$ with a spot size of $650 \mu \mathrm{m}$. After XPS, the sample surface was etched using focused argon-ion sputtering to investigate the chemical compositional depth profile (Thermo Scientific K-Alpha). Finally, the photoelectron spectrum resulting from the core energy levels of yttrium 3D states was deconvoluted by a fitting software program (Thermo Fisher Scientific, Inc., Waltham, MA, USA) to estimate the contributions from bonding with fluorine elements. 


\section{Results and Discussion}

Figure 1 depicts the XRD scan patterns of $\mathrm{YF}_{3}$ films deposited on $\mathrm{Al}_{2} \mathrm{O}_{3}$ substrate at 400, 500, 600 , and $700{ }^{\circ} \mathrm{C}$. All $\mathrm{YF}_{3}$ samples were polycrystalline, and their structural orientations depended on the substrate temperature in the deposition process. The (020) plane of the orthorhombic $\mathrm{YF}_{3}$ phase was formed at substrate temperatures above $500{ }^{\circ} \mathrm{C}$, which is in agreement with the reported data (JCPDS card files No. 74-0911) [11]. Moreover, the preferential orientation of the orthorhombic $\mathrm{YF}_{3}$ crystal structure differed in films fabricated at different temperatures. This might be attributed to the high kinetic energy imparted to $\mathrm{YF}_{3}$ molecules at high substrate temperatures, which enables them to migrate and rearrange on the substrate surface. $\mathrm{YF}_{3}$ samples fabricated at higher temperatures also showed a weak peak of the cubic $\mathrm{Y}_{2} \mathrm{O}_{3}$ phase (400) plane (JCPDS card files No. 79-1716), indicating contamination by oxygen atoms during the sputtering process [9]. As substrate temperature increases, $\mathrm{Y}_{2} \mathrm{O}_{3}$ formation might be favored by the higher instability of fluoride in the $\mathrm{YF}_{3}$ crystal lattice. Unstable $\mathrm{F}$ ions in the lattice can be gradually replaced by environmental oxygen atoms. Therefore, the number of oxygen atoms in the crystal lattice increases with increasing temperature, forming $\mathrm{Y}_{2} \mathrm{O}_{3}$ (see Figure 1). When $\mathrm{YF}_{3}$ film was deposited at a lower substrate temperature, an amorphous structure was formed. Amorphous film usually has a loose structure, resulting in greater thickness and a higher growth rate. In contrast, with increasing substrate temperature, the $\mathrm{YF}_{3}$ film became crystalline, and its crystal was relatively ordered. This indicates that a denser structure was found in the $\mathrm{YF}_{3}$ film grown at higher substrate temperatures, leading to its smaller thickness and lower growth rate. In TEM analysis, the $\mathrm{YF}_{3}$ films exhibited nanocrystalline grains with an average size of 5-20 nm (Figure 2). The regular ring-like electron diffraction pattern of a selected area (Figure 2, inset) implies a polycrystalline structure of $\mathrm{YF}_{3}$ film, consistent with the XRD result.

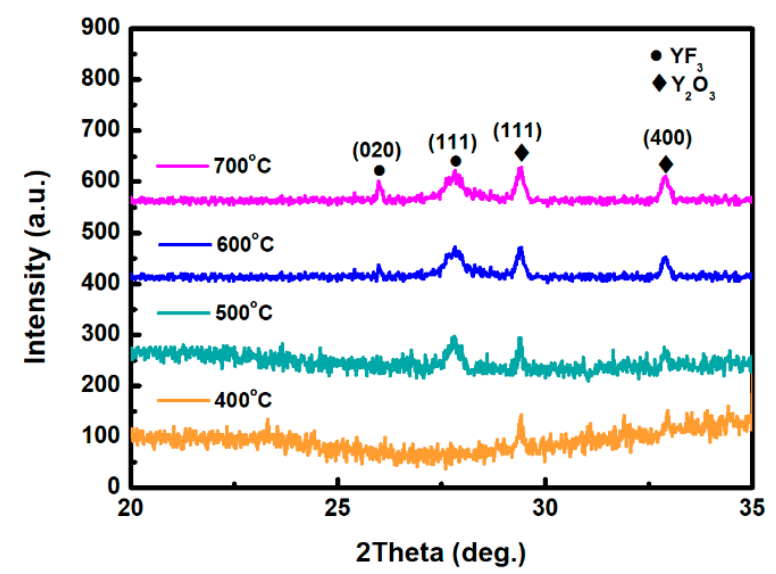

Figure 1. XRD patterns of the as-deposited yttrium fluoride $\left(\mathrm{YF}_{3}\right)$ films grown at 400, 500, 600, and $700{ }^{\circ} \mathrm{C}$.

Figure $3 a, b$ show the XPS survey spectra in the $0-1200 \mathrm{eV}$ range of the $\mathrm{YF}_{3}$ films before and after $\mathrm{CF}_{4} / \mathrm{O}_{2}$ plasma etching, respectively. To collect the atomic signals, all samples were bombarded by argon ions for $2 \mathrm{~min}$. The XPS peaks in the as-grown $\mathrm{YF}_{3}$ thin film (Figure 3a) correspond to Y, F, O, and $\mathrm{C}$ elements. The $\mathrm{Y}$ and $\mathrm{F}$ elements existed in the original $\mathrm{YF}_{3}$ film, and an $\mathrm{O} 1 \mathrm{~s}$ peak arose from oxygen contamination during the sputter deposition process. This result is consistent with previous reports [12]. After exposure to $\mathrm{CF}_{4} / \mathrm{O}_{2}$ plasma, the spectrum of the $\mathrm{YF}_{3}$ film exhibited an enhanced $\mathrm{F} 1 \mathrm{~s}$ peak and an additional $\mathrm{C}$ 1s peak. The former feature is attributed to the high fluorine content of $\mathrm{YF}_{3}$, and the latter indicates the formation of a carbon-polymer surface layer under fluorocarbon plasma etching (Figure $3 \mathrm{~b}$ ). Figure $4 \mathrm{a}, \mathrm{b}$ plot the compositions of the $\mathrm{YF}_{3}$ films as functions of sputtering time before and after exposure to the $\mathrm{CF}_{4} / \mathrm{O}_{2}$ plasma, respectively. Before exposure to the plasma, the maximum $\mathrm{F}$ content was $37 \%$ and the minimum $\mathrm{O}$ content was $32 \%$ (Figure $4 \mathrm{a}$ ). This result indicates a two-phase mixture of $\mathrm{YF}_{3}$ and $\mathrm{Y}_{2} \mathrm{O}_{3}$ in the film, consistent with a previous study that reported a 
deficiency of fluorine atoms during the sputter deposition process [13]. The maximum percentage of $\mathrm{F}$ atoms in the etched sample was $44.69 \%$, implying a fluorination layer on the $\mathrm{YF}_{3}$ specimen (Figure $4 \mathrm{~b}$ ). Similar results were observed in a previous study of surface fluorination by $\mathrm{CF}_{4} / \mathrm{O}_{2}$ plasma etching [14]. The carbon content on the $\mathrm{YF}_{3}$ surface decreased abruptly with sputtering time, indicating a very thin carbon polymer layer on the etched surface. This is because of interactions between the fluorocarbon plasma and Si-based materials, which generate carbon polymer and a $\mathrm{SiF}_{x} \mathrm{O}_{\mathrm{y}}$ reaction layer [15].

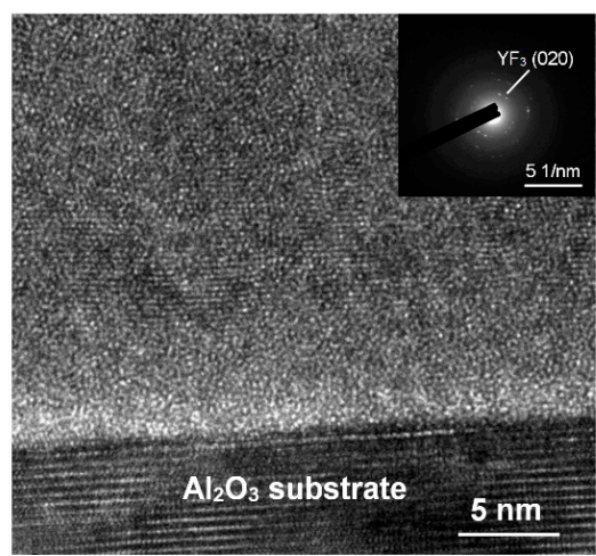

Figure 2. TEM microstructure and selected area diffraction (inset) of $\mathrm{YF}_{3}$ film.
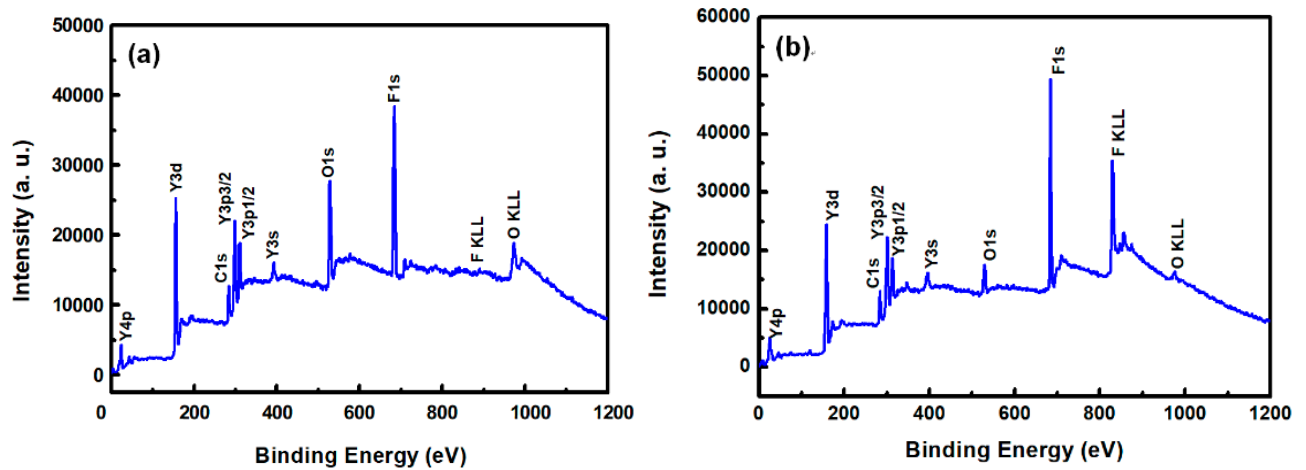

Figure 3. XPS survey spectra of the surfaces of the $\mathrm{YF}_{3}$ thin films (a) before and (b) after exposure to $\mathrm{CF}_{4} / \mathrm{O}_{2}$ plasma (under bombardment with argon ions for two minutes).
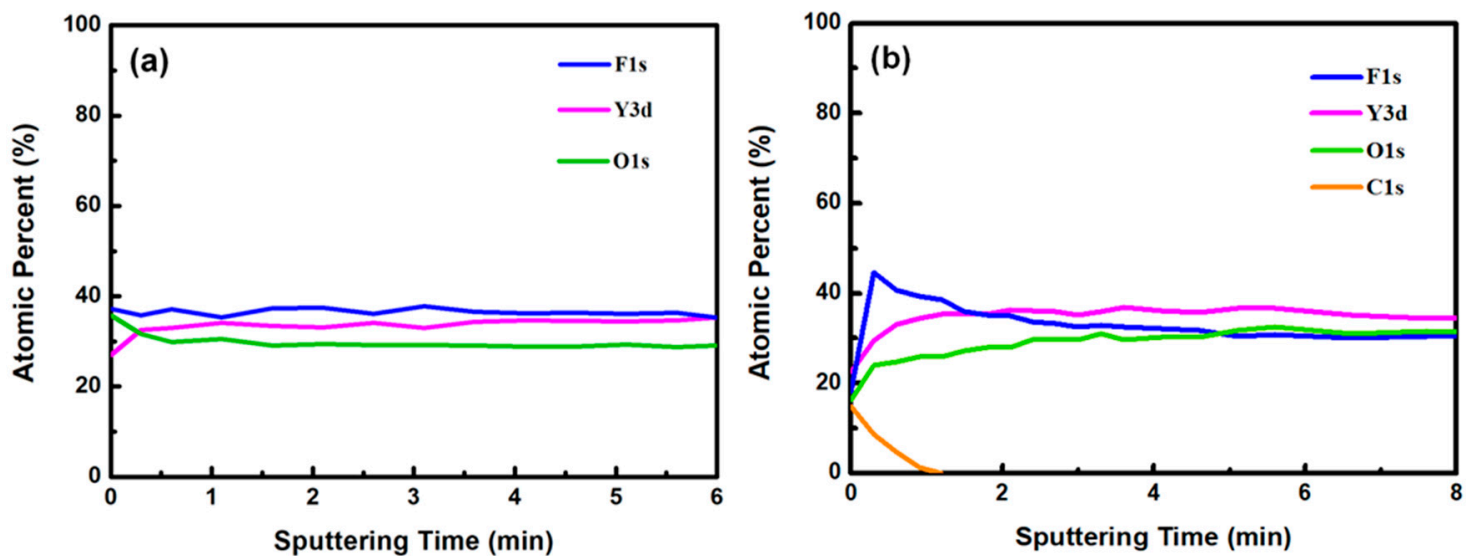

Figure 4. Atomic percentages of $\mathrm{YF}_{3}$ film versus sputtering time (a) before and (b) after surface exposure to $\mathrm{CF}_{4} / \mathrm{O}_{2}$ plasma. 
Figure 5 shows the XPS spectra of yttrium atoms of the $\mathrm{YF}_{3}$ film after $\mathrm{CF}_{4} / \mathrm{O}_{2}$ plasma etching. In the curve-fitted XPS spectra of the $\mathrm{YF}_{3}$ film, two peaks represent two bonding sources for $\mathrm{Y}$ cations, that is, the $\mathrm{Y} 3 \mathrm{~d}$ peak splits into a doublet $\left(\mathrm{Y}_{3} \mathrm{~d}_{5 / 2}\right.$ and $\mathrm{Y}_{3} \mathrm{~d}_{3 / 2}$ electrons) with a binding-energy separation of $2 \mathrm{eV}$. The two yttrium bonding sources are consistent with the XPS standard [16]. The $Y 3 d_{5 / 2}$ and $Y 3 d_{3 / 2}$ peaks in the spectrum of the as-deposited $Y F_{3}$ film (Figure 5a) deconvolute into four peaks. The two peaks located at higher binding energies (159.4 and $161.4 \mathrm{eV})$ correspond to $\mathrm{Y}-\mathrm{F}$ bonding in the $\mathrm{YF}_{3}$ film, whereas those at lower binding energies (157 and $159 \mathrm{eV}$ ) are ascribed to $\mathrm{Y}-\mathrm{O}$ bonding. In the XPS spectra of etched $\mathrm{YF}_{3}$ film surface, the peaks are more intense than in the un-etched specimen (Figure 5b). Again, the strong doublet at higher binding energies (159.6 and $161.6 \mathrm{eV}$ ) and the weak doublet at lower binding energies (157 and $159 \mathrm{eV})$ correspond to $\mathrm{Y}-\mathrm{F}$ and $\mathrm{Y}-\mathrm{O}$ bonding, respectively. The higher XPS binding energy of the $\mathrm{Y}-\mathrm{F}$ bonding can be attributed to the higher electronegativity of fluorine atoms (4.0) than oxygen atoms (3.5) [17]. Consequently, more electrons are transferred to fluorine, decreasing the electron density around the cation and enhancing the binding energy. Meanwhile, the intensity ratio of $\mathrm{Y}-\mathrm{F}$ to $\mathrm{Y}-\mathrm{O}$ bonds was estimated as 2.1 on etched $\mathrm{YF}_{3}$ films, indicating strong chemical interaction between the $\mathrm{YF}_{3}$ films and the fluorocarbon plasma.
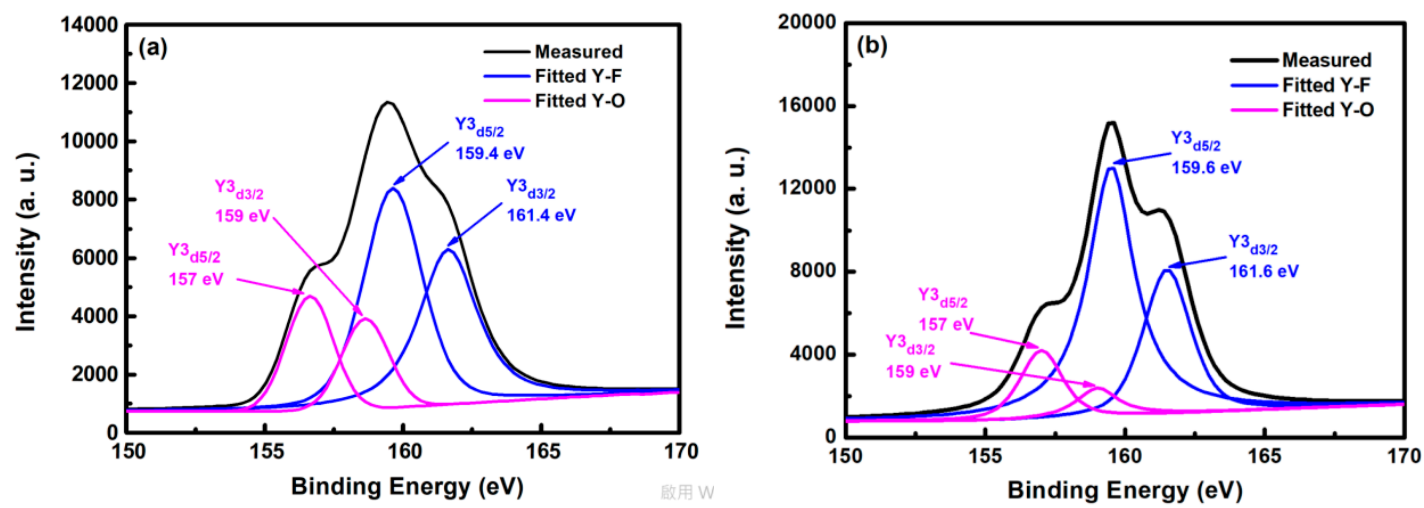

Figure 5. X-ray photoelectron spectra of $\mathrm{YF}_{3}$ film (a) before and (b) after exposure to fluorocarbon plasma.

To evaluate the plasma erosion resistance of as-deposited $\mathrm{YF}_{3}$ films, the etching rate of the $\mathrm{YF}_{3}$-coated $\mathrm{Al}_{2} \mathrm{O}_{3}$ substrate was measured after exposure to the $\mathrm{CF}_{4} / \mathrm{O}_{2}$ plasma for different etching times. The etching rate of bare $\mathrm{Al}_{2} \mathrm{O}_{3}$ crystal was used as the reference. Figure 6 shows that the etching depths of both samples linearly increased with increasing etching time. After $30 \mathrm{~min}$, the etching

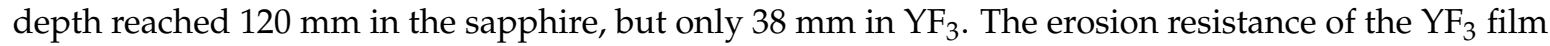
to $\mathrm{CF}_{4} / \mathrm{O}_{2}$ plasma etching was more than three times higher than that of sapphire crystal. This is attributed to the chemical stability of $\mathrm{YF}_{3}$ in a chemical environment dominated by fluorocarbon plasma. The surface morphologies and roughness of the $\mathrm{YF}_{3}$ films etched for different lengths of time were measured by AFM measurements, with a scanning area of $5 \mathrm{~m}^{2}$. The surface roughness results are shown in Figure 7 . The etching time of the $\mathrm{CF}_{4} / \mathrm{O}_{2}$ plasma did not remarkably influence the surface roughness of the $\mathrm{YF}_{3}$ film.

Figure $8 \mathrm{a}$, $\mathrm{b}$ show the surface microstructures of $\mathrm{YF}_{3}$ and $\mathrm{Al}_{2} \mathrm{O}_{3}$ samples, respectively, after the etching experiment. The micrographs were acquired by optical microscopy (OM). The right and left images in each panel show the un-etched and etched surfaces, respectively. The step height of the $\mathrm{Al}_{2} \mathrm{O}_{3}$ sample changed after $\mathrm{CF}_{4} / \mathrm{O}_{2}$ plasma etching. These images confirm the hardness and stronger $\mathrm{CF}_{4} / \mathrm{O}_{2}$ corrosion resistance of the $\mathrm{YF}_{3}$ films compared to conventional $\mathrm{Al}_{2} \mathrm{O}_{3}$ substrate. 


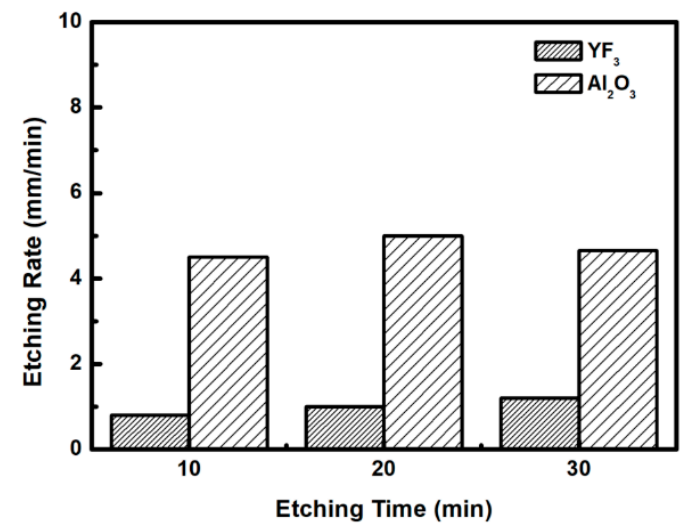

Figure 6. Etching depths of the $\mathrm{YF}_{3}$ film and $\mathrm{Al}_{2} \mathrm{O}_{3}$ substrates after different $\mathrm{CF}_{4} / \mathrm{O}_{2}$ plasma exposure times.

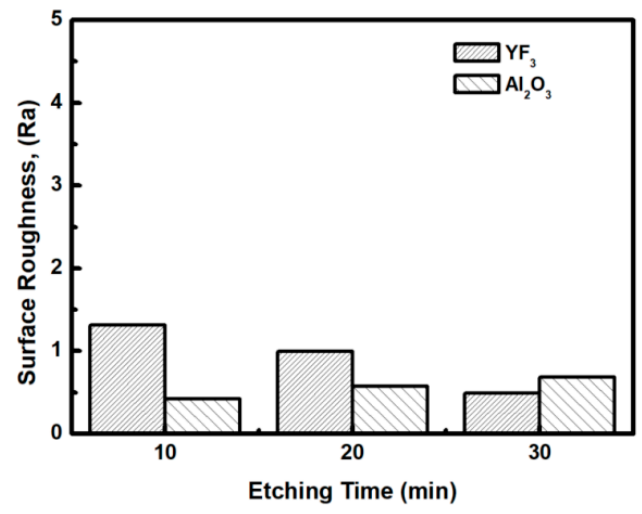

Figure 7. Surface roughness of $\mathrm{YF}_{3}$ and $\mathrm{Al}_{2} \mathrm{O}_{3}$ exposed to fluorocarbon plasma for different etching times.

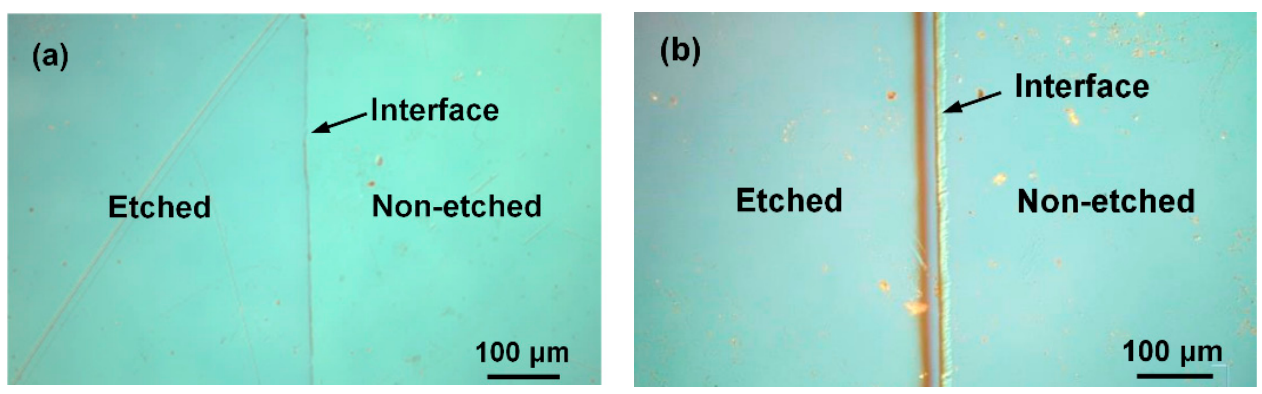

Figure 8. Optical micrographs of the (a) $\mathrm{YF}_{3}$ and (b) $\mathrm{Al}_{2} \mathrm{O}_{3}$ substrates after exposure to fluorocarbon plasma.

$\mathrm{AlF}_{3}$ is a typical fluoride of $\mathrm{Al}_{2} \mathrm{O}_{3}$ materials [4]. The boiling temperature of $\mathrm{YF}_{3}\left(2230^{\circ} \mathrm{C}\right)$ is higher than the sublimation temperature of $\mathrm{AlF}_{3}\left(1275^{\circ} \mathrm{C}\right)$. Hence, $\mathrm{YF}_{3}$ is more stable and more difficult to vaporize than $\mathrm{AlF}_{3}$. Therefore, its fluorinated layer can be removed by a physical sputtering process. The sputtering yields of the films are inversely proportional to sublimation enthalpies of their compounds [18]. The sublimation enthalpy of $\mathrm{YF}_{3}(481 \pm 21 \mathrm{~kJ} / \mathrm{mol})$ is higher than that of $\mathrm{AlF}_{3}(301 \pm 4 \mathrm{~kJ} / \mathrm{mol})$. Moreover, the enthalpy of formation of the metal-oxygen bond is lower in $\mathrm{YF}_{3}\left(-392 \mathrm{~kJ} \mathrm{~mol}^{-1}\right)$ than in $\mathrm{Al}_{2} \mathrm{O}_{3}\left(-279 \mathrm{~kJ} \mathrm{~mol}^{-1}\right)$. Therefore, $\mathrm{YF}_{3}$ is chemically more stable than $\mathrm{Al}_{2} \mathrm{O}_{3}$ [19]. In particular, $\mathrm{YF}_{3}$ is extremely stable under the fluorocarbon plasma etching process.

Figure 9 shows a cross-sectional HRTEM image of the $\mathrm{YF}_{3}$ film after $\mathrm{CF}_{4} / \mathrm{O}_{2}$ plasma exposure. Continuous and nearly-complete lattice fringes were observed near the surface, indicating that the $\mathrm{YF}_{3}$ ceramic crystalline lattice was not distorted by the fluorine plasma irradiation. Furthermore, 
the d-spacings of the near surface of film were $3.131 \AA$ (blue dotted circle) and $2.621 \AA$ (red dotted circle), very close to the d-spacings of the altered layers of yttrium oxyflouride (YOF): $3.147 \AA$ (006) and $2.698 \AA$ (104) [11]. The thin YOF layer formed on the $\mathrm{YF}_{3}$ surface plays a protective role, suppressing the particle generation during $\mathrm{CF}_{4} / \mathrm{O}_{2}$ plasma etching process. The reaction and formation of an altered $\mathrm{YOF}$ layer has been reported previously [14]. Therefore, $\mathrm{YF}_{3}$ film is a very attractive plasma-corrosion-resistant material that produces fewer contamination particles during the semiconductor fabrication process.

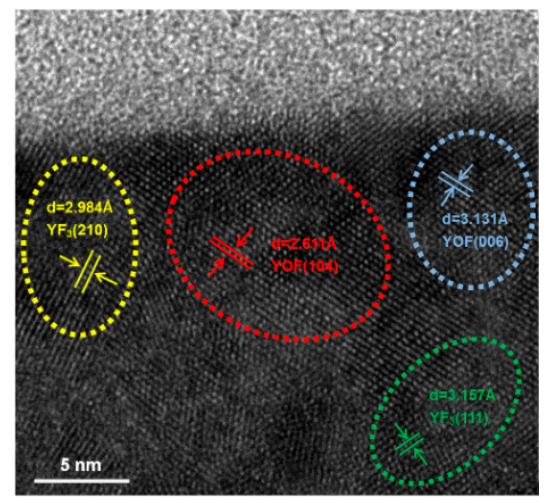

Figure 9. Cross-sectional high-resolution transmission electron microscopy (HRTEM) image of the $\mathrm{YF}_{3}$ film after exposure to fluorine plasma.

\section{Conclusions}

$\mathrm{YF}_{3}$ films were successfully deposited through radio frequency magnetron sputtering on sapphire substrates at different temperatures. HRTEM and XRD results revealed polycrystalline $\mathrm{YF}_{3}$ films with an orthorhombic structure. XPS results confirmed the superior chemical stability of $\mathrm{YF}_{3}$ film after fluorocarbon plasma treatment. The robustness of $\mathrm{YF}_{3}$ film was confirmed to be more than that of $\mathrm{Al}_{2} \mathrm{O}_{3}$ film after the plasma exposure. The $\mathrm{YF}_{3}$ film is expected to provide a more protective barrier than $\mathrm{Al}_{2} \mathrm{O}_{3}$ or quartz plates in the fluorine plasma etching process.

Author Contributions: Conceptualization: W.-K.W.; Methodology: Y.-X.L., Y.-J.S. and W.-K.W.; Data curation: Y.-X.L., Y.-J.S. and W.-K.W.; Writing-original draft preparation: Y.-X.L., Y.-J.S. and W.-K.W.; Writing一review and editing: W.-K.W.

Funding: This research was funded by the Ministry of Science and Technology of Taiwan (No. 107-2221-E-212-004).

Acknowledgments: The authors wish to express their sincere gratitude for the technical support from the Advanced Industry Technology Centre of National Chung Hsing University, Taiwan.

Conflicts of Interest: The authors declare no conflict of interest.

\section{References}

1. Kim, D.M.; Kim, K.B.; Yoon, S.Y.; Oh, S.Y.; Kim, H.T.; Lee, S.M. Effects of artificial pores and purity on the erosion behaviors of polycrystalline $\mathrm{Al}_{2} \mathrm{O}_{3}$ ceramics under fluorine plasma. J. Ceram. Soc. 2009, 117, 863-867. [CrossRef]

2. Zavareh, M.A.; Sarhen, A.A.D.M.; Razak, B.B.; Basirun, W.J. Plasma thermal spray of ceramic oxide coatingon carbon steel with enhanced wear and corrosion resistance for oil and gas applications. Ceram. Int. 2014, 40, 14267-14277. [CrossRef]

3. Fukumoto, H.; Fujikake, I.; Takao, Y.; Eriguchi, K.; Ono, K. Plasma chemical behavior of reactants and reaction products during inductively coupled $\mathrm{CF}_{4}$ plasma etching of $\mathrm{SiO}_{2}$. Plasma Sources Sci. Technol. 2009, 18, 045027. [CrossRef]

4. Kitamura, T.; Mizuno, H.; Kato, N.; Aoki, I. Plasma-erosion properties of ceramic coating prepared by plasma spraying. Mater. Trans. 2006, 47, 1677-1683. [CrossRef]

5. Duc, L.M.; Tan, C.M.; Luo, M.; Leng, I.C.H. Maintenance scheduling of plasma etching chamber in wafer fabrication for high-yield etching process. IEEE Trans. Semicond. Manuf. 2014, 27, 204-211. [CrossRef] 
6. Iwasawa, J.; Nishimizu, R.; Tokita, M.; Kiyohara, M.; Uematsu, K. Plasma-resistant dense yttrium oxide film prepared by aerosol deposition process. J. Am. Ceram. Soc. 2007, 90, 2327-2332. [CrossRef]

7. Mun, S.Y.; Shin, K.C.; Lee, S.S.; Kwak, J.S.; Jeong, J.Y.; Jeong, Y.H. Etch defect reduction using $\mathrm{SF}_{6} / \mathrm{O}_{2}$ plasma cleaning and optimizing etching recipe in photo resist masked gate poly silicon etch process. Jpn. J. Appl. Phys. 2005, 44, 4891-4895. [CrossRef]

8. Kim, D.M.; Oh, Y.S.; Kim, S.; Kim, H.T.; Lim, D.S.; Lee, S.M. The erosion behaviors of $\mathrm{Y}_{2} \mathrm{O}_{3}$ and $\mathrm{YF}_{3}$ coatings under fluorocarbon plasma. Thin Solid Films 2011, 519, 6698-6702. [CrossRef]

9. Lin, T.K.; Wuu, D.S.; Huang, S.Y.; Wang, W.K. Characteristics of yttrium fluoride and yttrium oxide coatings for plasma process equipment prepared by atmospheric plasma spraying. Jpn. J. Appl. Phys. 2016, 55, 126201. [CrossRef]

10. Chakravarthy, Y.; Bhandari, S.; Chaturvedi, V.; Pragatheeswaran, A.; Nagraj, A.; Thiyagarajan, T.K.; Ananthapadmanaban, P.V.; Das, A.K. Plasma spray deposition of yttrium oxide on graphite, coating characterization and interaction with molten uranium. J. Eur. Ceram. Soc. 2015, 35, 781-794. [CrossRef]

11. Chai, G.D.; Dong, G.P.; Qiu, J.R.; Zhang, Q.Y.; Yang, Z.M. Phase transformation and intense $2.7 \mathrm{~mm}$ emission from Er3+ oped $\mathrm{YF}_{3} / \mathrm{YOF}$ submicron-crystals. Sci. Rep. 2013, 3, 1598. [CrossRef] [PubMed]

12. Pei, L.; Jiapi, Z.; Yuankun, Z.; Jiecai, H. Preparation and optical properties of sputtered-deposition yttrium fluoride film. Nucl. Instrum. Methods Phys. Res. Sect. B 2013, 307, 429-433. [CrossRef]

13. Quesnel, E.; Berger, M.; Duca, D.; Pelle, C.; Pierre, F. Near-UV to IR optical characterization of $\mathrm{YF}_{3}$ thin films deposited by evaporation and ion beam processes. Proc. SPIE 1996, 2776, 366-372.

14. Lin, T.K.; Wang, W.K.; Huang, S.Y.; Tasi, C.T.; Wuu, D.S. Comparison of erosion behavior and particle contamination in mass-production $\mathrm{CF}_{4} / \mathrm{O}_{2}$ plasma chambers using $\mathrm{Y}_{2} \mathrm{O}_{3}$ and $\mathrm{YF}_{3}$ protective coatings. Nanomaterials 2017, 7, 183. [CrossRef] [PubMed]

15. Matsui, M.; Tatsumi, T.; Sekine, M. Observation of surface reaction layers formed in highly selective $\mathrm{SiO}_{2}$ etching. J. Vac. Sci. Technol. 2001, 19, 1282-1888. [CrossRef]

16. Moulder, J.F.; Stickle, W.F.; Sobol, P.E.; Bomben, K.D. Handbook of X-ray Photoelectron Spectroscopy; Physical Electronics: Eden Prairie, MN, USA, 1995; p. 10.

17. Zhong, H.X.; Hong, J.M.; Cao, X.F.; Chen, X.T.; Xue, Z.L. Ionic-liquid-assisted synthesis of $\mathrm{YF}_{3}$ with different crystalline phases and morphologies. Mater. Res. Bull. 2009, 44, 623-628. [CrossRef]

18. Cao, Y.C.; Zhao, L.; Luo, J.; Wang, K.; Zhang, B.P.; Yokota, H.; Ito, Y.; Li, J.F. Plasma etching behavior of $\mathrm{Y}_{2} \mathrm{O}_{3}$ ceramics: Comparative study with $\mathrm{Al}_{2} \mathrm{O}_{3}$. Appl. Surf. Sci. 2016, 366, 304-309. [CrossRef]

19. Brunetti, B.; Piacente, V.; Scardala, P. Torsion vapor pressure and sublimation enthalpies of aluminum trifluoride and aluminum trichloride. J. Chem. Eng. Data 2009, 54, 940-944. [CrossRef] 